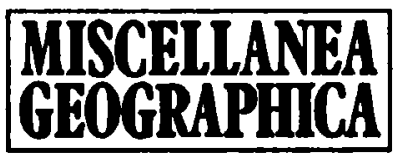

WARSZAWA 1994 Vol. 6

Małgorzata Gutry-Korycka, Piotr Werner

\title{
INFLUENCE OF GLOBAL CLIMATE CHANGES ON SPATIAL DISTRIBUTION OF AIR TEMPERATURE AND PRECIPITATION IN POLAND
}

\section{GOAL OF RESEARCH AND EMPIRICAL DATA}

Changes in the course of global geophysical processes may affect the size and time schedule of the elements of the hydrological cycle in a catchment. Water balance, which constitutes a quantitative approach to this cycle at the scale of the particular catchment, is highly sensitive to global changes of the air temperature and precipitation that determine vertical and horizontal water exchange.

Using uncertain scenarios of changes that regard a global climatic warming as the main reason for unstationary circulation of water in a catchment, a simulation was carried out of the mean annual values of the air temperature and precipitation in Poland.

Simulation of the effect of global climatic changes may be carried out in two ways:

1. The expansion of the air temperature field into the Taylor sequence $T=f\left(\lambda_{n} \varphi\right.$ and $\left.H\right)$ in relation to three position coordinates, i.e. latitude and longitude, as well as elevation above sea level H (Stopa-Boryczka et. al.. 1990), permits a description of deformation of field of the air temperature as a result of hypsometry. The obtained empirical model of simulation of spatial distribution of the air temperature and the knowledge of basic geographical factors can be used for time and spatial forecast of global climatic changes in Poland.

2. The grid model which was used in these investigations takes into account the rhythm of changes of field of the air temperature and precipitation in relation to geographical coordinates. Thus it was assumed that spatial distribution of selected climatological elements (real and generated field) due to hypsometry and interpolation are in the quantititive proportion. In other words, a relative quantitative system of real and generated isotherms does not change.

The air temperature was generated on the basis of average values for 30 
years (1951-1980) from 58 meteorological gauges (1989). In order to generate the field for precipitation, average yearly values of total precipitation for 90 years (1891-1980) from 57 gauges were used (Chrzanowski 1988).

\section{GENERATION OF NORMAL VALUES OF THE AIR TEMPERATURE AND PRECIPITATION WITH ASSUMED SCENARIOS OF CLIMATIC CHANGES}

Forecasts of climate changes are usually related to the level of double concentration of $\mathrm{CO}_{2}$, and the greenhouse effect. Climatologists point to a positive trend of the air temperature, but it is more difficult to estimate a precipitation change trend due to its great stochastic variability both in time an space.

The sensitivity of a catchment to climatic changes is most often considered in relation to changes of radiation balance whose index is the air temperature, and to changes in humidity balance which is essentially dependent on atmospheric precipitation. Models of global changes of climate developed in recent years, particularly in the U.S.A. and Great Britain, permit a creation of scenarios of changes based on these particular meteorological elements.

In the Division of Water Resources of the Institute of Geophysics of the Polish Academy od Sciences Professor Z. Kaczmarek has been conducting research for several years with a view to developing and verifying selected climatic scenarios within the territory of Poland.

The first approach involves the simulation of hydrological processes using physically justified mathematical models of catchments and assumed scenarios of changes of meteorological elements. The other approach is aimed at defining the degree of sensitivity of the particular processes of the hydrological cycle to climatic warming due to the greenhouse effect.

Two scenarios were chosen corresponding to double concentration of $\mathrm{CO}_{2}$ in the atmosphere calculated for Europe according to two global models of circulation, (General Circulation Model or GCM): GFDL model (Geophysical Fluid Dynamic Laboratory) and the GISS model (Goddard Institute for Space Studies). Results for these models for the region of Central Europe were obtained from the National Center for Atmospheric Research (NCAR) in Boulder, USA, version of the model before 1989 (Scenariusze... 1992). Both global GCM models produce scenarios of climatic changes which envisage increase in the air temperature as well as in atmospheric precipitation. Output data from these global models appear as files of values for temperature and precipitation corresponding to the nodes in the data net for scenario $\left(1 \times \mathrm{CO}_{2}\right)$ zero, that is to natural conditions, and data resulting from a doubled value $\left(2 \times \mathrm{CO}_{2}\right)$. Numerical values of assumed climatic chan- 
ges were defined for nodes of the geographical grid of intervals 1 degree of latitude $\times 1$ degree of longitude.

The region of Central Europe was adopted to be limited by 45 degrees and 55 degrees of latitude and by 10 degrees and 25 degrees of geographical longitude. The area outside Poland, was divided into 150 unit entry files of 1 degree of latitude $\times 1$ degree of longitude. To carry out the so-called downscaling of climate information from the GCM and $\mathrm{GCM}_{\mathrm{s}}$ models in the territory of Poland, several numerical procedures need to be applied.

The base map of Poland used was 1:3000000 in quasi-stereographical secant projection in the system type of GUGiK 1980 (Grygorenko 1985). Transformation of the geographical system into the system of regular (Cartesian) coordinates was made, using the ADS procedure in the programme PC ARC/INFO. The base of meteorological data was created using the programme Dbase IV. From this data base the values of geographical location of climatological stations were generated using the procedure PROJECT, which permits a transformation to quasi-stereographical projection. Next, using the procedure TRANSF/RM the location of stations was transformed into the system of cartographical coordinates. The SURFER package was chosen for interpolation and presentation of the results obtained.

As an interpolation net for the spatial model of climatological elements a square grid of cells $2 \times 2 \mathrm{~mm}$ on the same scale as the base map was used (thus, the dimension of the field cell of interpolation amounted to $6 \mathrm{~km} \times 6 \mathrm{~km}$ ). In the interpolation the area outside the territory of Poland was "covered up". The method of kriging for spatial interpolation was applied to construct the field of the air temperature. The method of kriging is based on the assumption that expected value is equal to the difference $\left[z(x)-z(x+h)^{2}\right]$, where $z(x)$ is the value of a meteorological variable at the station, while $(h)$ indicates the distance between the stations. The method is confined to estimation of cordinates $(z)$ at the nodes of the grid on the basis of values at the measuring points. The method assumes that the mean value of errors during estimation amounts to $O$, while the variance is the least possible.

For interpolation of precipitation, the method of reverse distances between climatological gauges was used (Tański 1990). The interpolation procedures permitted the creation of simulation maps in the two-dimensional form of isopleths (isohyets and isotherms) (Figs, 1, 2, 3 and 5, 6, 7) and three-dimensional block diagrams representing the spatial distribution of the analysed meteorological elements (Figs. 8, 9, 10 and 11, 12,13).

The numerical and graphical areas obtained also made in possible to construct charts representing the relation of the numerical value of the meteorological element to the area limited by the isoline of the same value as the above-mentioned isoline. Curves of total annual precipitation distribution illustrate the share of Poland enclosed between the successive isohyets or isotherms of mean annual values (Figs. 4, 14). Finally, the maps produced were compared. 


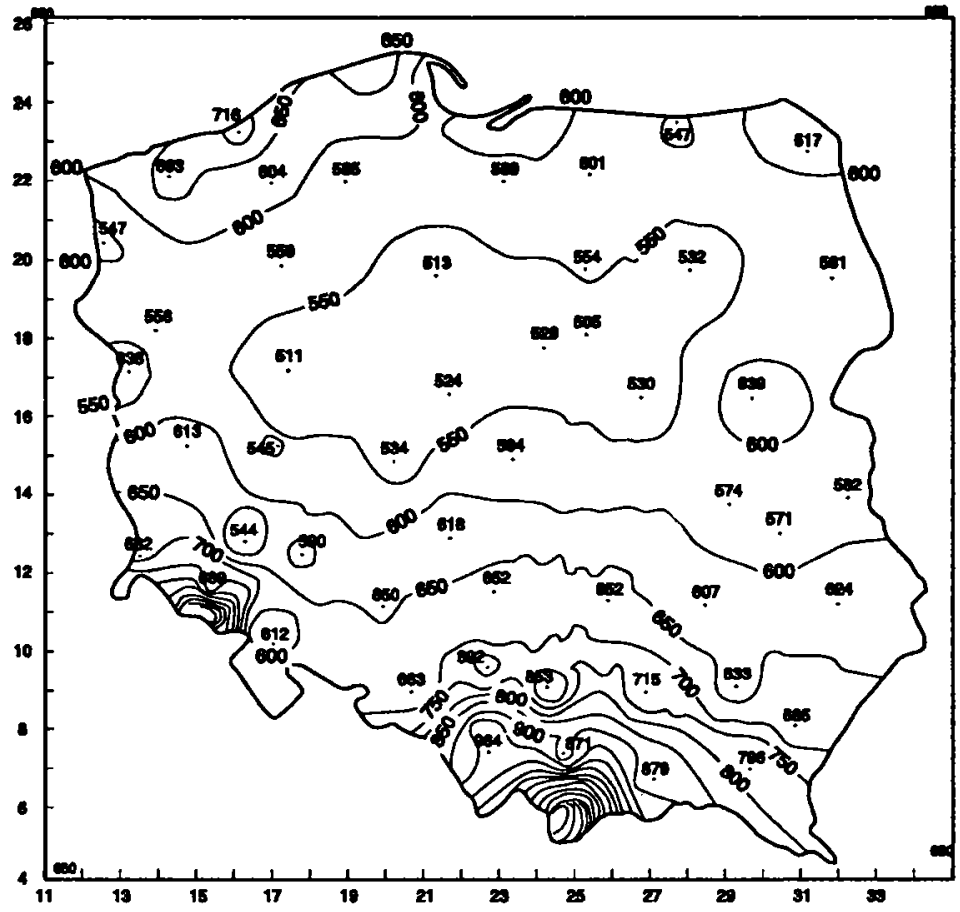

Fig. 1. Normal precipitation in (mm) in (18911980), scenario 0

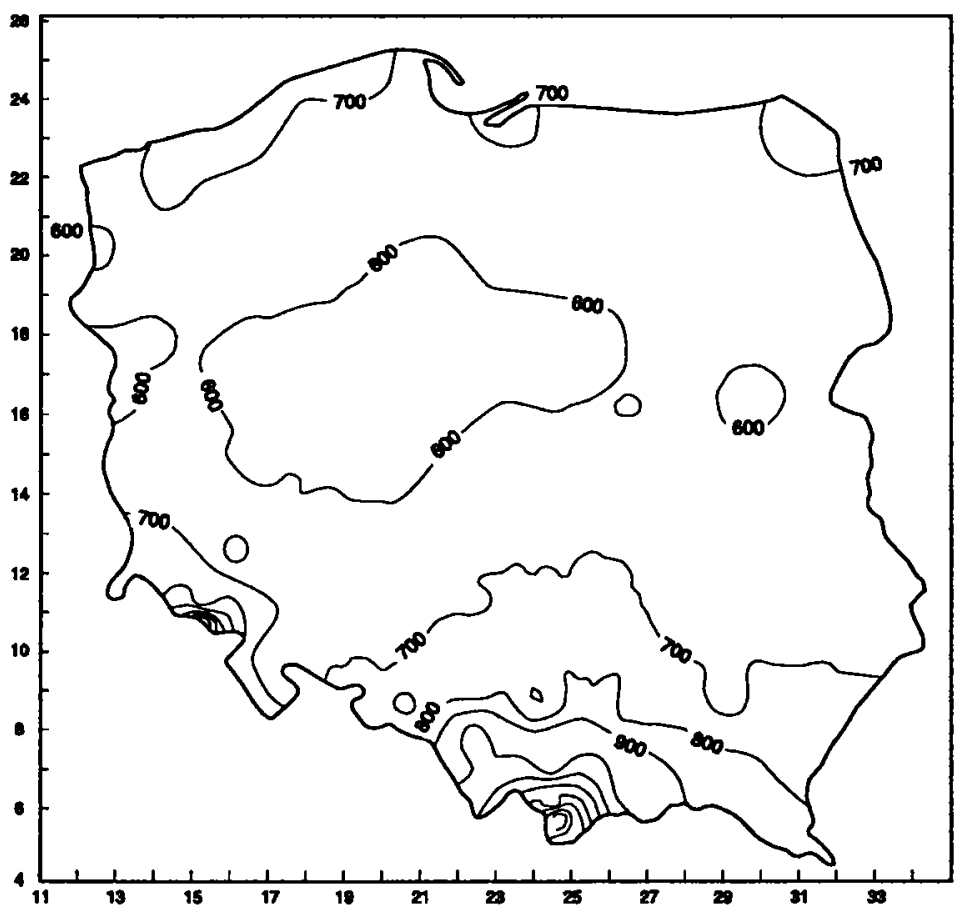

Fig. 2. Generation of normal precipitation in $(\mathrm{mm})$, scenario $\left(2 \times \mathrm{CO}_{2}\right)$ - according to GFDL model 


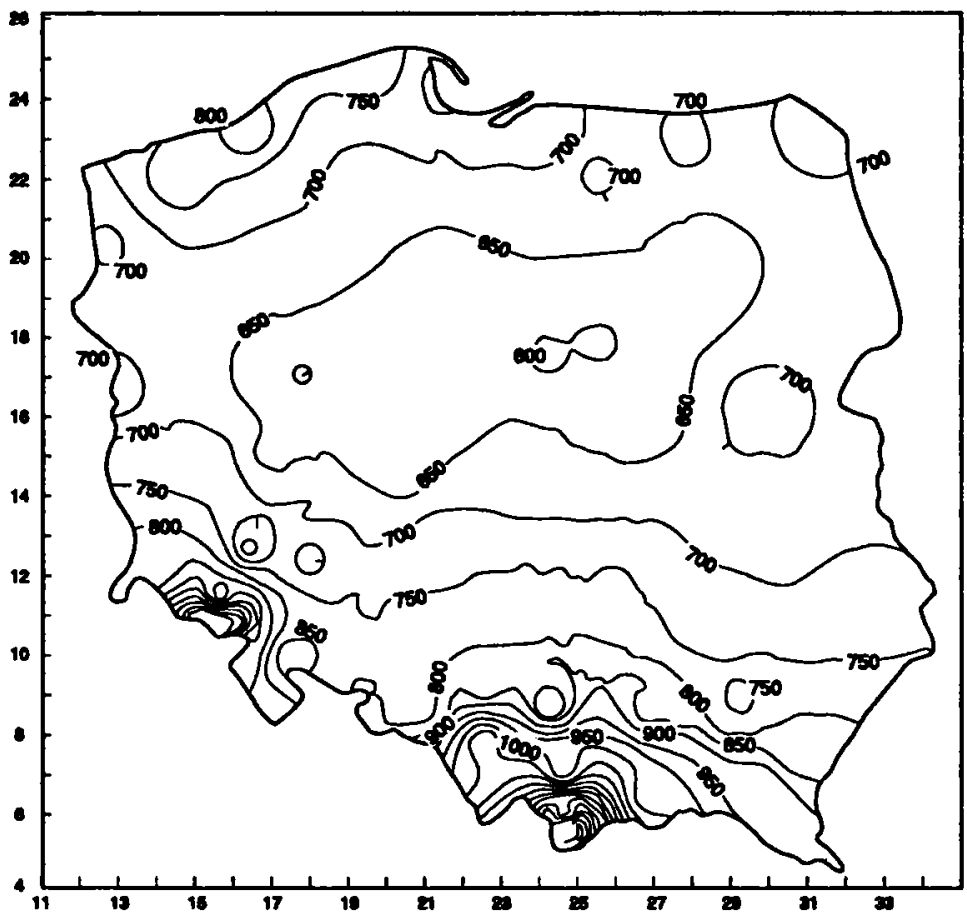

Fig. 3. Generation of normal precipitation in (mm), scenario $\left(2 \times \mathrm{CO}_{2}\right)-$ according to GISS model

The disadvantage of the simulation is that the grid model takes into consideration mathematical but not geographical interpolation; therefore in the areas with high gradients of meteorological elements, especially in the mountains and uplands, there may be large differences between the empirical values and those obtained from linear interpolation. Thus, deviations will appear in areas with a low density of the measuring stations.

The graphical and numerical areas obtained were taken as a basis for finding a method of transforming $\mathrm{GCM}_{\mathrm{s}}$ based predictions to sub-scaling models.

The input simulation models obtained from GISS and GFDL models differ slightly. The selected scenarios of climatic changes envisage an increase in air temperature by about $4^{\circ} \mathrm{C}$ and increase in precipitation over most of the year by $10 \mathrm{~mm}$ (except for September).

In the GISS model, the change in precipitation ranges from $+1.1 \mathrm{~mm}$ to $13.2 \mathrm{~mm}$, while the GFDS model expects the increase of precipitation to be slightly below $10 \mathrm{~mm}$, with the exception of August, when the increase is $>\mathbf{3 0} \mathrm{mm}$, and June, September and October, when precipitation decreases by approximately $5 \mathrm{~mm}$ (Ozga-Zielińska 1992).

The interpolated fields of changes in air temperature and precipitation compared with normal real precipitation and simulated precipitation 


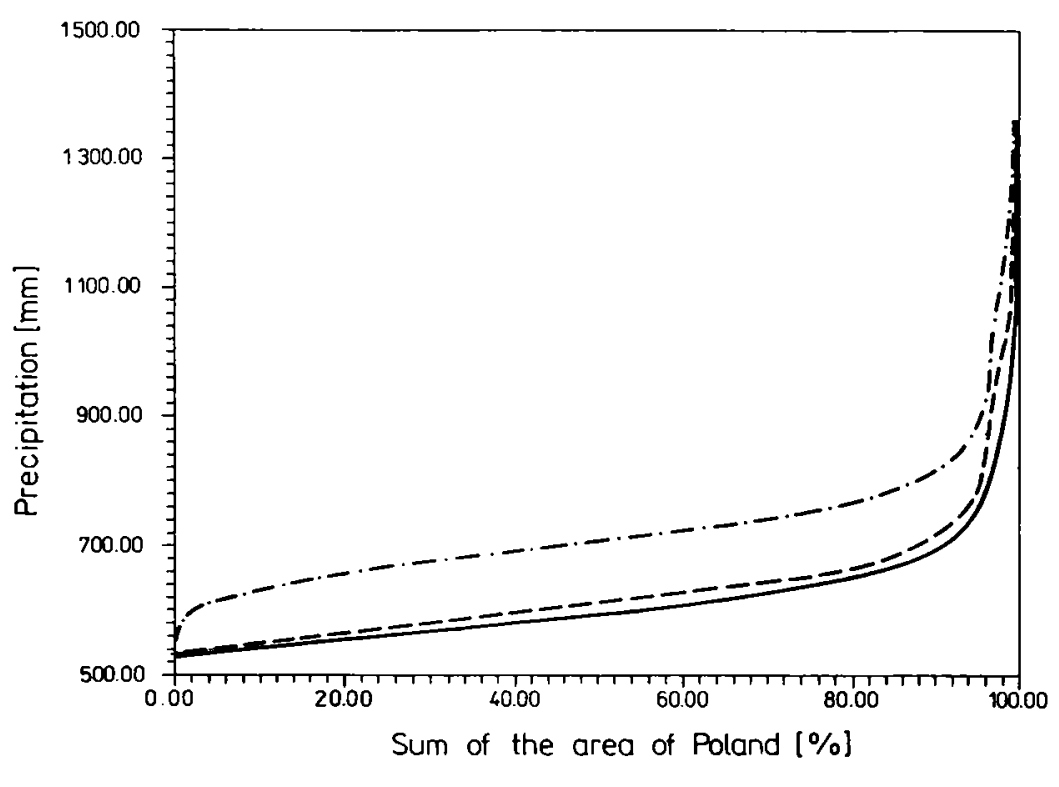

$-1 \quad----2 \quad----3$

Fig. 4. Areal distribution of normal precipitation in Poland (\%)

1 - period 1891-1980 (scenario 0); 2 - generation according to GFDL (scenario $2 \times \mathrm{CO}_{2}$ ) model; 3 - generation according to GISS (scenario $2 \times \mathrm{CO}_{2}$ ) model; axis $\mathrm{x}$ - sum of area of Poland covered by the given isopleth (\%); axis y - average annual precipitation (mm)

provided grounds for estimation of differences in values of these elements obtained from global models GISS and GFDL.

The areal average annual precipitation total (half of the area of Poland) in natural conditions amounts to $639 \mathrm{~mm}$. According to the GISS model it will reach $749 \mathrm{~mm}$, while according to the GFDL model annual precipitation is expected to amount to $655 \mathrm{~mm}$ (Fig. 4).

Over half of Poland's territory the mean air temperature in natural conditions totals $7.7^{\circ} \mathrm{C}$, while according to the scenario of doubled $\mathrm{CO}_{2}$ contents in the GISS model it will amount to $10.5^{\circ} \mathrm{C}$, and in the GFDL model it will reach $11.9^{\circ} \mathrm{C}$ (Fig. 14).

\section{CONCLUSIONS}

Climate is described according to the statistics of meteorological phenomena observed over the period of at least 30 years. Research on the time and spatial structure of the natural fields of the air temperature and precipitation (scenario 0 ) has satisfied his requirement.

This research may be a starting point for combining GCM's used to forecast climatic changes with hydrological models. It paves the way for developing global models for grid nodes on a smaller scale. The stochastic 


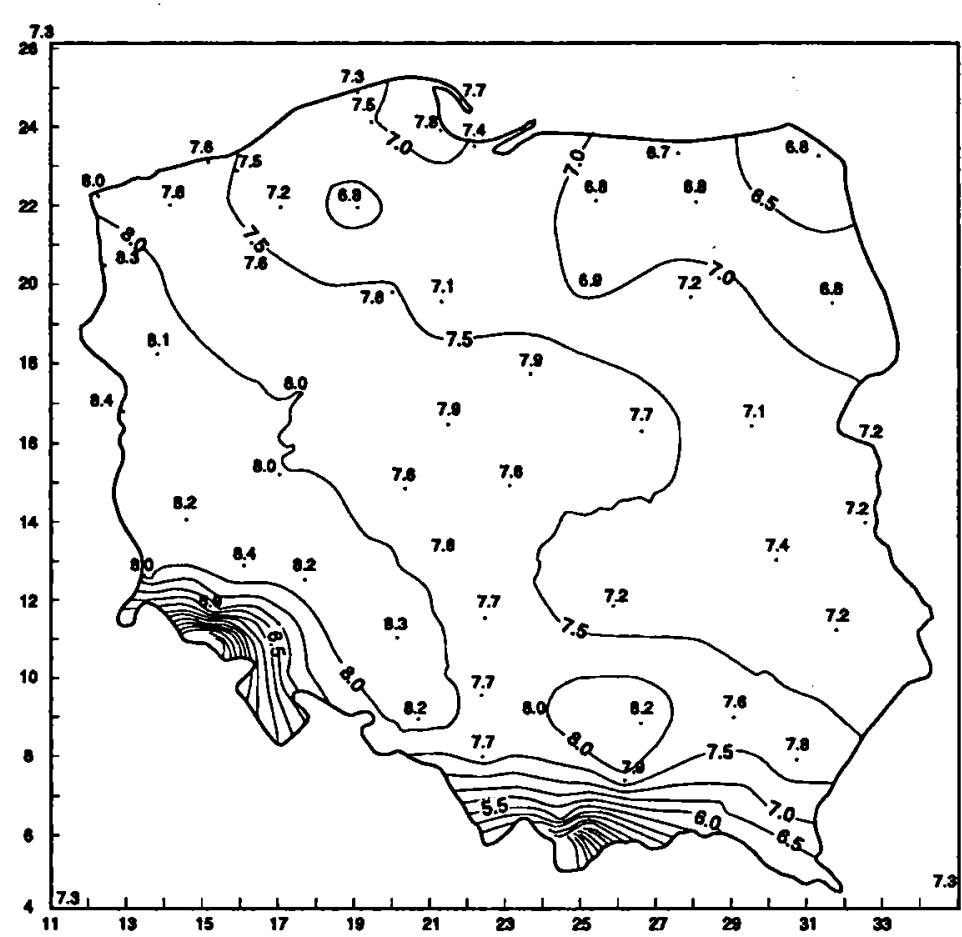

Fig. 5. The average air temperature $\left({ }^{\circ} \mathrm{C}\right)$ in (1951-1980), scenario 0

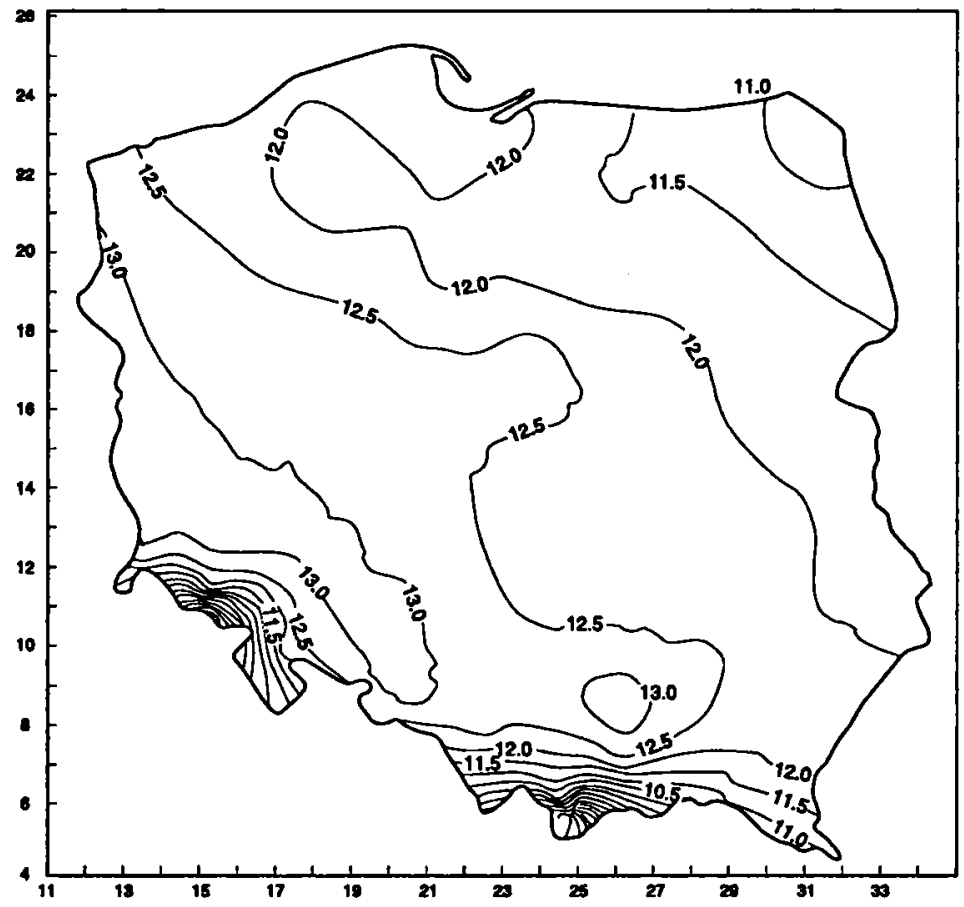

Fig. 6. Generation of the average air temperature in $\left({ }^{\circ} \mathrm{C}\right)$, scenario $\left(2 \times \mathrm{CO}_{2}\right)$ - according to GFDL model 


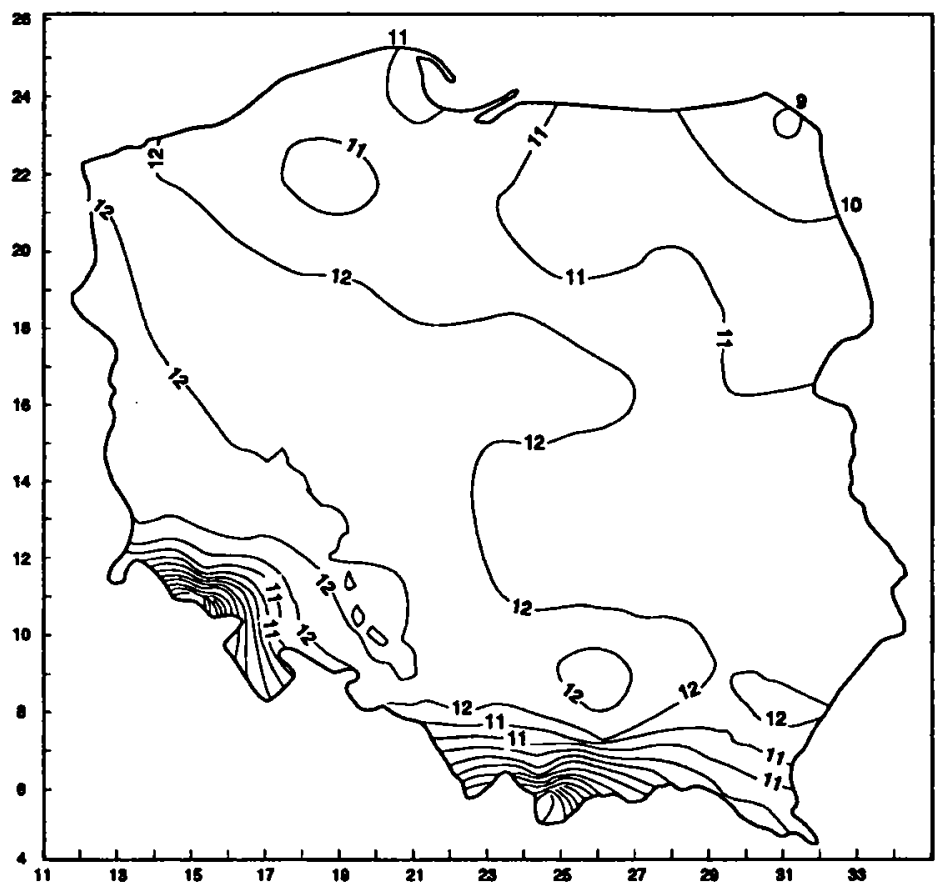

Fig. 7. Generation of the average air temperature in $(\mathrm{oC})$, scenario $\left(2 \times \mathrm{CO}_{2}\right)-$ according to GISS model

methods applied permitted a determination of the local spatial structure of daily meteorological elements coupled with large-scale information.

The spatial distribution of isotherms and isohyets obtained as a result of simulation, though it provides an approximate picture, could be a point of departure for modelling hydrological processes and their distribution under the assumed scenarios of climatic changes. This, however, requires a construction of a spatio-temporal model linking local changes of the air temperature and precipitation with changes influenced by predicted global transformation of atmospheric circulation.

Methods of simulation using 90 -year and 30 -year sequences provide sufficient statistical material for a relatively precise estimation.

Both approaches to simulation of fields of meteorological variables in long and short time intervals will be applied to combine global models with large-scale and small-scale modls, given the scenarios of climatic changes. 



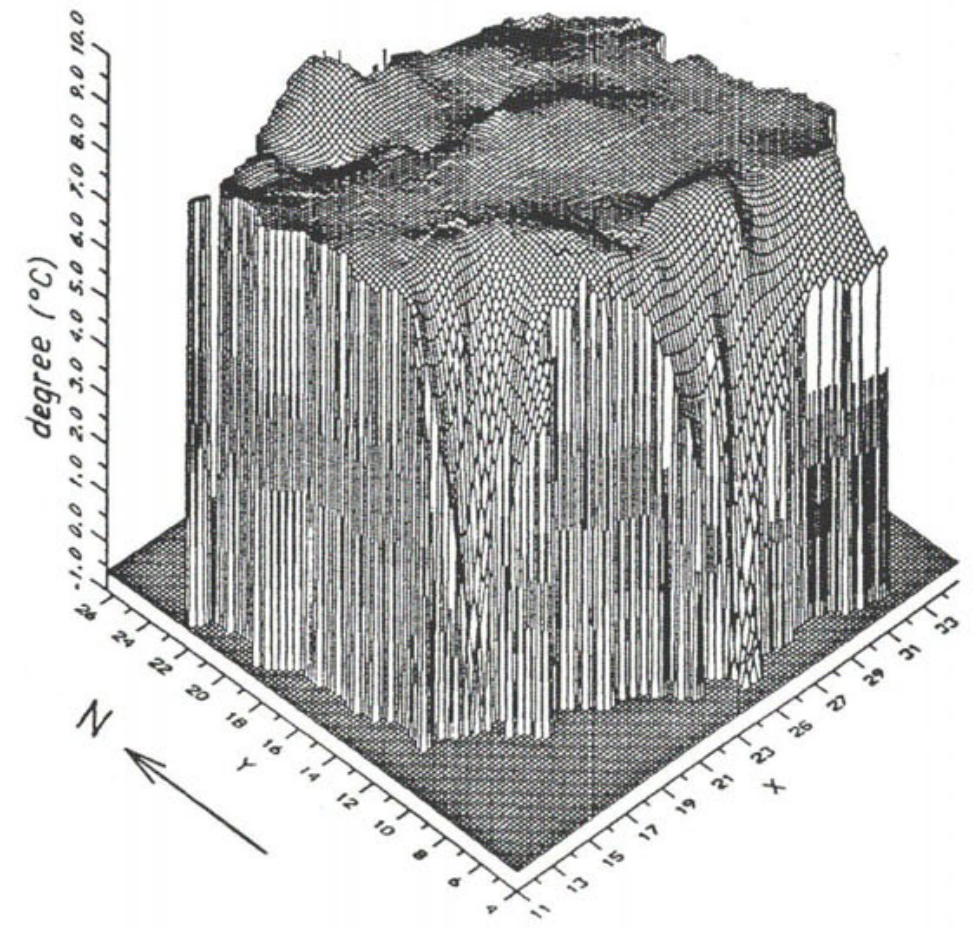

Fig. 11. Three-dimensional distribution of the average air temperature (1951-1980), scenario 0

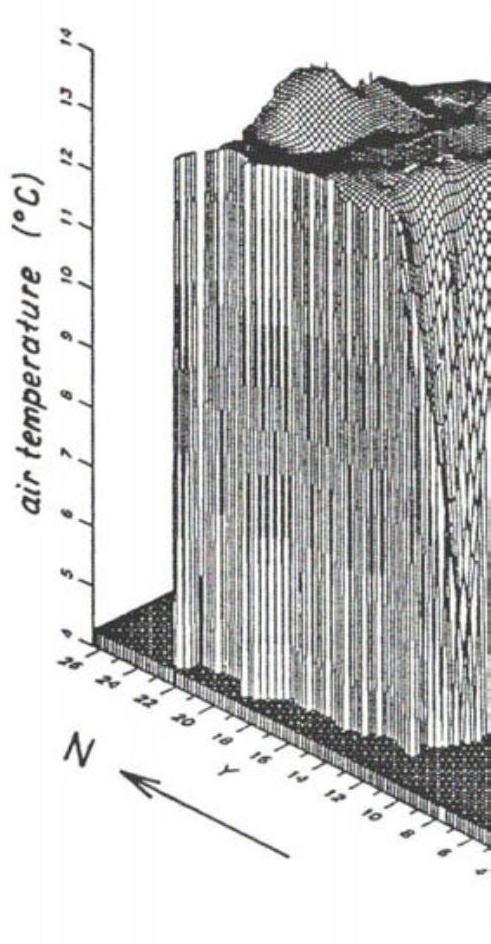

Fig. 12. Three-dimensional distribution of scenario $\left(2 \times \mathrm{CO}_{2}\right)-$ according to GFDL $\mathrm{n}$ 

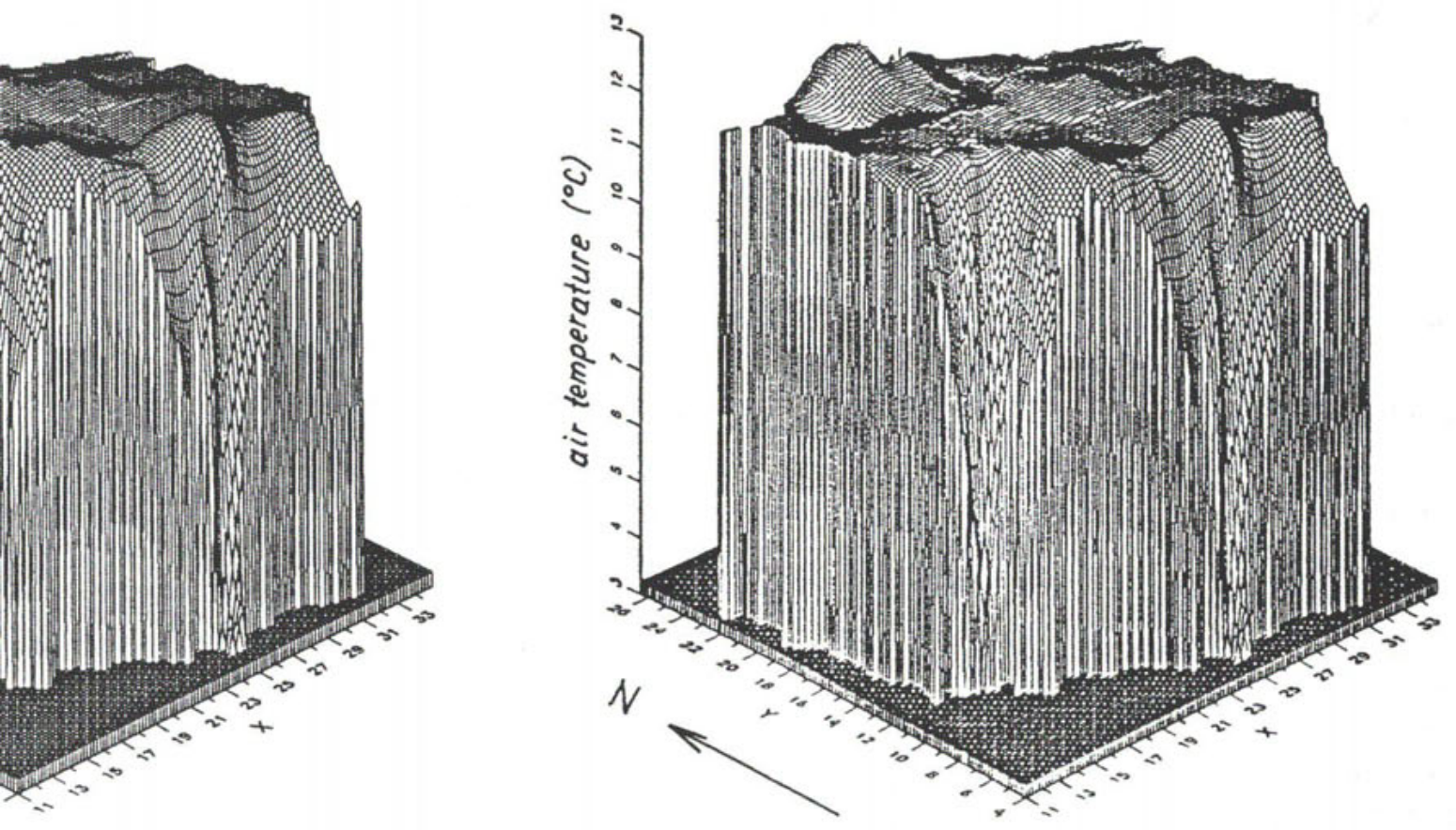

the average air temperature,

Fig. 13. Three-dimensional distribution of the average air temperature, scenario $\left(2 \times \mathrm{CO}_{2}\right)-$ according to GISS model 

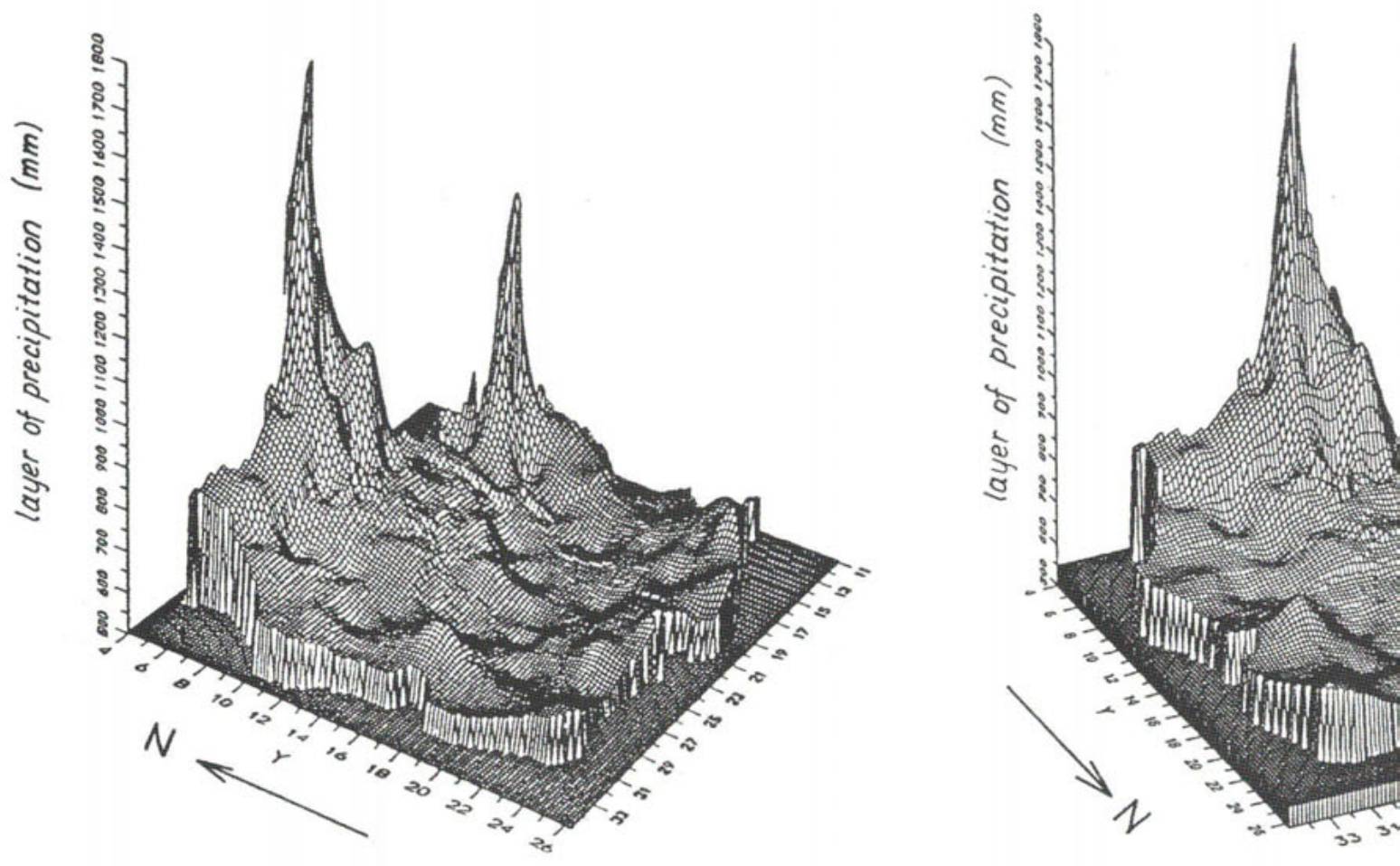

Fig. 8. Three-dimensional distribution of normal precipitation in ( $\mathrm{mm}$ ), in 1891-1980, scenario 0

Fig. 9. Three-dimensional distribution o scenario $\left(2 \times \mathrm{CO}_{2}\right)$ - according GFDL $n$ 

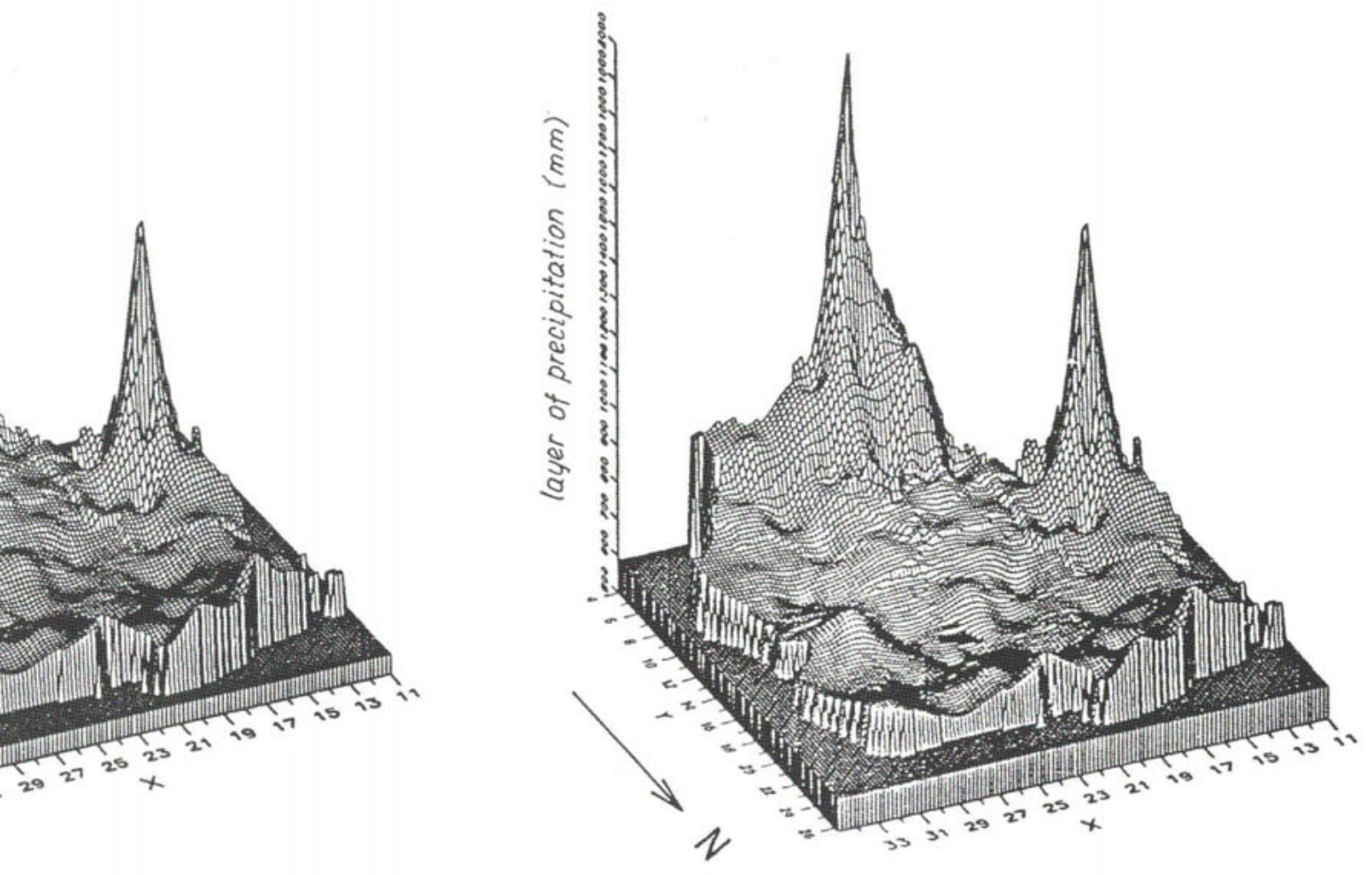
